\title{
Firm Innovation Systems: Perspectives of Researches on State-owned Key Enterprises
}

\begin{abstract}
Based on the origin of the innovation theory and the technological innovation models of Rothwell, this paper puts forward four-generations of evolutionary models using the firm innovation system: "Internal R\&DOriented Innovation System", "Internal and External Collaborative Innovation System", "Highly StrategicOriented Innovation System" and "Ecological Innovation System". This paper dwells on the characteristics and relationship between each innovation system, and the role in the enterprise innovation especially the State-owned Key Enterprises innovation, so as to provide a theoretical and practical basis for the design and improvement of the Stateowned Key Enterprises innovation system.
\end{abstract}

Keywords: firm innovation system, state-owned key enterprises, ecology, evolution

\section{Overview}

After Schumpeter (1912) took the initiative in systematically defining the concept of innovation in 1912, innovation was once considered to be a one-way, successive and gradual linear process formed from basic research through aspects such as applied research, design, trial manufacture, manufacture and sales. But practice indicates that innovation is a diverse process blending complex feedback mechanisms between factors and other elements rather than a simple linear process. Consequently, system innovation theory and comprehensive innovation

Manuscript received September 10, 2014; accepted January 1, 2015

Jin Chen $(\bowtie)$

School of Economics and Management, Tsinghua University, Beijing 100084, China

Email: chenjin@sem.tsinghua.edu.cn

Shu-fang Huang

School of Public Affairs, Zhejiang University, Hangzhou 310027, China

Qing-rui Xu

School of Management, Zhejiang University, Hangzhou 310058, China theory have come into being. The concept of the innovative system was also proposed after, including the national innovation system (Freeman, 1987, 1988, 1995; Lundvall, 1988, 1992; Nelson, 1993), the regional innovation system (Cooke, 1992, 2004), the industrial innovation system (Malerba, 2002) and the firm innovation system (Chen, 1999; Chen \& Chen, 2007; Xu, Xie \& Zheng, 2004). Before the 1980s, relationships between enterprises were often competitive; but since the late 1980s and 1990s, with the rise of knowledge-based economy, the advent of the big data era, increasingly the demand for personalized products and the increasingly complex, changing business environment, companies have had to reexamine their own values, social responsibilities and sustainable development issues; the traditional firm innovation system has been further challenged. Afterwards, the proposal of enterprise ecosystem theory and open innovation theory have further sublimated innovation theory.

From the perspective of the technological innovation evolution, Rothwell divided the technological innovation process into five generations of models: 1st generation, "technology push" (1950s-mid 1960s); 2nd generation, "market pull" (1960s-1970s); 3rd generation, "coupling model" (late 1970s-mid 1980s); 4th generation, "integrated model" (early 1980s-early 1990s); and 5th generation, "systems integration and networking model" (since the 1990s). Later, the model has been improved and developed into the sixth generation "national innovation system" (21st century). On this basis, this paper proposes four generations of innovative system evolutionary models from the enterprise perspective: 1st generation, "Internal R\&D-Oriented Innovation System"; 2nd generation, "Internal and External Collaborative Innovation System"; 3rd generation, "Highly Strategy-Oriented Innovation System"; and 4th generation, "Innovation Ecosystem".

This paper explores the evolutionary background of the firm innovation system, characteristics of each generation of the innovation system, interrelations and differences between systems and their impacts on firm innovations by a combined literature and case study method, thereby providing the theoretical and practical basis for the design and improvement of the central enterprises system. 


\section{First generation: Internal R\&D-Oriented Innovation System}

In the 1950s-1960s, owing to the development of materials technology, biotechnology, electronic information technology and other new technologies, the position and role of science and technology in innovation were recognized; and the internal R\&D system of the enterprises represented the firm innovation system, such as Xerox's Palo Alto Research Center (PARC), AT\&T's Bell Laboratories and IBM's T. J. Watson Laboratory. Companies conducted research and development internally, achieved technological breakthroughs through internal research and development, designed and developed new products, conducted trial manufacturing, production and manufacturing, brought new products to the market through internal channels, provided service and technical support, and gained market dominance relying on technologies. Meanwhile, they implemented a strict patent control over all key elements; the superiority of internal R\&D formed technical barriers against the entry of other competitors, which was considered to be the enterprises' valuable strategic assets and reliable guarantee able to ensure technological security and exclusivity, thus helping them maintain a leading position in technology. It was the key to enhancing core competitiveness and maintaining a competitive advantage for enterprises, and even placing obstacles preventing competitors from entering many markets, which was characterized by the strict control and vertical integration of innovation, and thus was a kind of closed independent innovation model. The firm Innovation System under such background was referred to as the innovation system centered on internal $\mathrm{R} \& \mathrm{D}$, whose basic idea was more $R \& D$, equals more innovation. During this period, the position of the market in the enterprise innovation was yet to be taken seriously; besides, enterprises were yet to be fully aware of the importance of the corporate boundary breakdown and external cooperation to the enterprise innovation.

The internal R\&D-Oriented Innovation System laid a solid foundation for the enhancement of the enterprises' innovation capabilities. For example, the Sany Group lays great emphasis on building an internal R\&D system. The group has established a research institute-based $R \& D$ architecture worldwide in accordance with the "professional layout, integrated multi-regional distribution" ideas. Each business division is established with more than 30 specialized research institutes, which are mainly engaged in the research and development of various products. Under each research institute, there are also 221 research subinstitutes which are divided by different specializations. A central research institute is set up at the headquarters, which is responsible for the unified management of $R \& D$ projects, patents, technical standards, PDM, experimental testing and industrial design, thus forming a dual-track matrix R\&D management model combining business divisions' vertical management with central research institute's horizontal management, thereby achieving the efficient allocation of innovation resources, and ensuring the high efficiency of $R \& D$ innovation. Relying on research institutes and sub-institutes, the Sany Group has built a cluster-type technology platform including 1 national-level and 3 provincial-level enterprise technical centers, 3 engineering technology research centers, 2 postdoctoral research stations and 2 academician and expert workstations for supporting collaborative design of the 32 global research institutes. The group has also built the industry's first "Science \& Technology Information Port" as well as the R\&D management systems such as the R\&D project management platform, the standardized information management platform and the patent application management platform to achieve the sharing of innovative knowledge sharing and R\&D digital management. Meanwhile, the Sany Group has also launched various forms of university-industry research cooperation projects. The group has established research institutes at universities, and collaboratively established innovation laboratories and alliances. The group has also cooperated with over 30 universities to undertake more than 20 national projects. $5 \%-7 \%$ of sales revenue is invested into R\&D every year. In 2011, the investment reached 5.78\%, more than 400 independent $R \& D$ projects were completed, more than 100 new products were launched, and a number of the 863 Program key projects were tackled. However, Sany's system has yet to fully integrate R\&D with manufacturing and marketing.

\section{Second generation: Internal and External Collaborative Innovation System}

In the late 1960s, with increasingly fierce competition among enterprises and a significant increase in productivity, companies began to realize the important role of the market in the innovation process, and the markets demand was regarded as a source of ideas which guided research and development. Companies began to focus on how to use the existing technological change and diversification to achieve a larger market share. In the 1970s, with the occurrence of the two oil crises, there had been a serious oversupply of products, and enterprises further impacted the market.

Mowery and Rosenberg (1979) found that the enterprise innovation process began to integrate production and marketing resources on the basis of $\mathrm{R} \& \mathrm{D}$, and access to potential sources of innovation from multiple channels; the enterprise innovation system started to change from a single $R \& D$ system to the direction of interconnected science, technology, marketing and manufacturing, in order for quick and accurate response to the market. Uncertainty of enterprise innovation was not only manifested in the technological uncertainty, but also in the market, strategic 
and financial uncertainties. Teece (1986) explained why some technologically leading enterprises were not necessarily able to get first-mover advantage, while other companies quickly coping and marketing products were receiving a larger share of the market with product imitations, and he has pointed out that in addition to $\mathrm{R} \& \mathrm{D}$, innovation companies also needs to pay attention to complementary assets including the manufacturing and marketing capabilities. Innovative management must correctly coordinate and organize $\mathrm{R} \& \mathrm{D}$, marketing and production as none of the three are indispensable. Only by interaction among the three management modules can new innovative visions be instituted and become valuable practice.

In addition, due to the increasingly open business environment and increasingly fierce market competition, the closed internal innovation model became inefficient, which then made it difficult to meet the requirements of the enterprise innovation, and even hindered enterprise innovation to some extent. Chesbrough (2003a, 2003b) formally proposed the open innovation theory, and applied it in practice, helping companies build an open innovation system. The second generation firm innovation system is an innovation system based on collaboration and integration. Compared with the first generation system, the second generation firm innovation system not only integrates production, manufacturing and internal market resources, but also integrates external innovation resources through organizational boundary penetration. The enterprises' innovative ideas come, on the one hand, from the innovative ideas and activities of intra-organizational $\mathrm{R} \& \mathrm{D}$, manufacturing and marketing departments, and intra-enterprise collaborative strategies, human resources and data; and on the other hand, from the innovative ideas of extra-organizational major customers, service providers, research institutions, universities, and industry bodies, as well as market channels. The second generation innovation system incorporates the internal and external innovative ideas into the enterprise structure; the enterprises' internal innovative ideas can also enter the market through external channels, externalizing their existing businesses, in order to generate additional value.

Baosteel is a typical example of second generation innovation system. Baosteel has established a sound open technological innovation system and mechanism. Baosteel encourages all-involvement innovation, and fully mobilizes the innovation enthusiasm of scientific and technical personnel and frontline staff; mass technological innovation has contributed greatly to Baosteel's technological development. Baosteel established a "technological innovation chain" cooperating with users through the "early involvement" model and helps users of the technological improvement model to accelerate the development of new product varieties, and establishes a good trust relationship and strategic partnership with users to achieve reciprocity and mutual benefit. To take full advantage of external sources to make up for its own lack of power, Baosteel attaches great importance to the development and use of external scientific and technological resources, and has established an external cooperation and innovation mechanism combining international cooperation and university-industry-research cooperation. Baosteel actively carries out multi-channel, multi-level and multi-form international cooperation and exchanges, consciously takes the initiative to introduce advanced foreign technologies and intelligences, and sends technological personnel to learn, explore and work with overseas peers, thereby achieving efficient multi-channel allocation of innovation resources. Baosteel has established brand new absorptive innovative ideas, implemented a combination of "initiative choice" and "independent research" which strengthens the utilizing and integrating capabilities of scientific and technological resources, accelerates independent development, and ultimately achieves mastery and control over key technologies. At present, Baosteel has transited from the technological importer to the following stage as the partial "leader" stage. By taking the road of open technological development, Baosteel stimulates all employees' passion for innovation, and fully absorbs and utilizes the leading technologies of users, suppliers, internationally renowned steel companies, universities and research institutions.

\section{Third generation: Highly Strategy-Oriented Innovation System}

From the perspective of enterprise management, innovation is a process through which a new idea is born, researched, developed, trial-manufacturing and the manufacturing are done, and first commercialization is achieved. To turn innovative technology into a highly recognized innovative product on the market, the "Darwin" sea must be crossed, and a number of processes need to be gone through. Therefore, innovation is a strategic activity concerning the development direction of enterprises. The importance of strategic management in enterprise innovation has become increasingly prominent, giving birth to the 3 rd generation "Highly Strategy-Oriented Innovation System".

Figure 1 depicts the relationship between innovation and strategic management. The relationship between enterprise innovation strategy and the overall enterprise strategy can

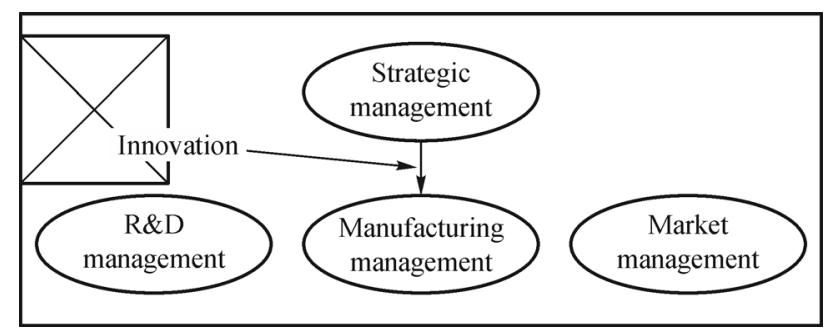

Figure 1. Relationship between innovation and strategic management. 
be described as follows: innovation strategy is a key component of the enterprise strategy, which should be consistent with the overall enterprise strategy. Innovation strategy serves for the overall enterprise strategy for the overall business strategy while having a promoting role in the overall business strategy. Enterprises' innovation strategy decision makers are inseparable from enterprise leadership governance system.

\subsection{Leading from the top}

The corporate CEO and senior management team's governance on innovation is the most important aspect of enterprise innovation, and the enterprises' innovation strategy decision makers are inseparable from the enterprise leadership governance system. The governance model of China's state-owned enterprises is the traditional governance model: which is characterized by relatively many short-term behaviors in terms of innovation, insufficient consideration of enterprise assets maintenance and appreciation, and lacking in the supporting culture and organization. Innovation types are biased toward government-driven projects, and independent innovations are lacking, which needs urgent improvement.

Jack Ma, the founder and CEO of Alibaba which has been successfully listed on the United States stock market, attaches great importance to enterprise innovation, has successfully designed the company's business model and management mechanism, and introduced the innovationsupporting venture capital institution and highly innovation-loving CFO. This pairs' leadership and governance system innovation has allowed Alibaba to become the world's most influential internet company in 10 years.

In addition, Roberts (2001) studied the contribution of CEO's technological background to enterprise innovation, and found that there was no significant correlation. Nevertheless, CEOs with good technological backgrounds are highly interrelated with the level of globalization of respective enterprises, which can bring more competitive technological strategies, reduce the break-even time, and are prone to accept the CTO's joining of board of directors or senior management team. Taking Schlumberger as an example, its CEO Paal Kibsgaard, executive vice president of technology and chief scientist Ashok Belani and executive vice president of corporate development and communication all have master's degrees in petroleum engineering, and strong technological backgrounds. It is exactly the technological backgrounds of core senior management that allow Schlumberger to always advocate technological innovation in the development process, and lead the development trend of the industry.

\subsection{Having a chief innovation officer (CINO)}

Ohmae (1991) has pointed out that Japanese enterprises usually have a talented strategist, and it is the strategic decision-making model dominated by the strategist that ultimately supports innovation activities of Japanese enterprises and then leads these enterprises to become successful. Except entrepreneurs, as mentioned above, CTO plays an important role in enterprise innovation. But CTO is primarily responsible for technical innovation and does not grasp the enterprise strategy and market enough, so chief innovation officers (CINOs) are born at the right moment. CINO is responsible to construct the innovation environment and culture, advance the transformation of innovation thought and provide moral and financial support for innovators. Deschamps and Nelson (2013) found that the high-level CINO model is more likely to ensure effective innovation governance than the lower-level innovation manager model.

Although CINO is a new position emerging in recent ten years, some international leading enterprises have been provided with the position of "CINO", such as AMD, Citigroup, Dupont, Humana, Owens-Corning, Airbus S.A. S., Coca-Cola, Pepsi-Cola, Xerox, etc. However, in some well-known enterprises, such as Johnson \& Johnson, even if there is no CINO, senior managers are designed for innovation. Few stated-backed Chinese enterprises are provided with CINO. Ping An of China appointed its chief innovation officer Tu Deyan in 2013, who is in charge of group innovation center and innovation fund and responsible to plan and promote the group's major business model innovation and technological application innovation, see clearly domestic and international great innovation trends and changes, and reflect on and drive the group's overall innovation. CINO can offer forward-looking, urgent strategic direction for enterprises, guiding enterprises to achieve sustainable innovation.

\section{Fourth generation: Ecological Innovation System}

Enterprise ecological innovation theory was proposed by Moore. Enterprise ecosystem is a dynamic structural system constituted by organizations or groups with certain interest relationships such as customers, suppliers, major manufacturers, investors, business partners, standard setting bodies, labor unions, government, public service agencies and other stakeholders. Iansiti and Levin (2004), Zahra and Nambisan (2012) have also thoroughly elaborated the enterprise ecosystem separately from the perspectives of dynamic niche, ecosystem structures and enterprise ecological network.

From a system perspective, the enterprise is no longer a member of a single industry, but a part of ecosystem which spans multiple industries. First, the ways by which various elements within the enterprise ecosystem interrelate and interact are the basis for the existence and development of the system, and the guarantee of the system stability as well. Secondly, a staggered, multi-dimensional network 
structure is formed among similar and dissimilar enterprises, and among upstream and downstream business chain members. What makes this network distinct from traditional networks are its complex, dynamic and crossover properties. Figure 2 depicts the cooperative nodes of traditional and ecological innovation networks: if there are $(n-1) / 2$ cooperative nodes between innovation bodies in a traditional innovation network, it will be possible for innovation bodies in an innovation ecological network to generate $n(n-1) / 2$ cooperative nodes, so the number of network nodes of innovation ecosystem is $n$ times greater than that of the traditional innovation network, which is precisely the network multiplier effect of the innovation ecosystem.

Advantages of inter-organizational collaboration brought about by network multiplier effect can be explained by transaction costs, resource-based views and strategic decision-making. In the aspect of transaction costs, inter-organizational collaboration can improve the return on assets, increase inter-organizational efficiency, and internalize and minimize the external transaction costs, thereby reducing unit costs. In the aspect of resource-based views, inter-organizational collaboration can help organizations achieve control over critical resources, and integrate complementary resources owned by different organizations. As for the strategic decision-making, interorganizational collaboration, it can coordinate and expand marketability, thus improving organizational performance. One example is Haike Group's ecological innovation system design; Haike Group builds a good ecosystem with ventures, peers, government, universities, research institutes and consulting firms with innovation council as the core, in order to promote innovation. The success of Apple, IBM, Procter \& Gamble and Eli Lilly also indicates that focusing on internal capabilities alone is not enough, the characteristics and needs of other eco-partners within the ecosystem must also be taken into account, and a dynamic open type of business ecosystem which is centered around the enterprise must be built as well.

Figure 3 depicts the enterprise ecosystem design. Innovation ecosystem is a coordination system of total innovation element resources, which not only involves ecosystem among enterprises, but also includes allinvolvement innovation within enterprises. Companies which have achieved good results in terms of allinvolvement innovation include Haier, Baosteel, Geely, etc. Since 2005 in which Geely was yet to strategically transform, "Yuandongli" Project representing all-involvement innovation has been officially launched throughout the company. "Yuandongli" Project is a series of management methods, theories and concepts for improving employee satisfaction, enhancing employees' sense of ownership, and stimulating employees' work enthusiasm and creativity. The company consolidates employees' vitality, employees' loyalty, stimulates employees' capabilities, and takes all possible means and measures to improve employee satisfaction. It allows the employees to become the real owners of the enterprise, fully mobilize all employees' initiative and enthusiasm for participating in corporate governance and creativity, fully tap employees' wisdom and potential, and transform employees' thoughts and ideas into a motivating force of enterprise development and into corporate market competitiveness, thereby promoting its sustainable development. To achieve the strategic transformation of "making the safest, most environmentally-friendly and most energy-efficient automobiles, and letting Geely automobiles can be found all around the world" and practice the quality policy of constant responsibility to brands and permanent customer satisfaction, Geely's specific foothold is their employees.

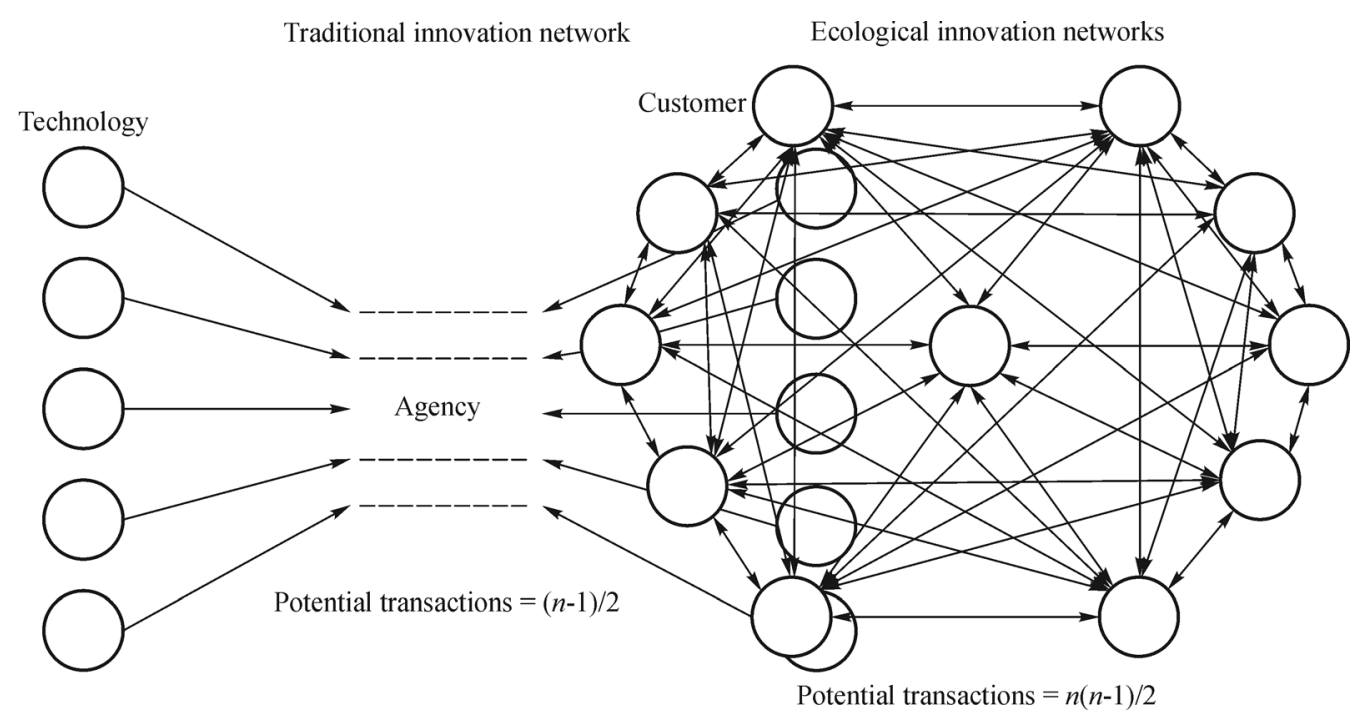

Figure 2. Cooperative nodes of traditional and ecological innovation networks. Adapted from The rainforest - the secret to building the next by Victor \& Greg, (2012). 
The promotion of "Yuandongli" Project has greatly accelerated the Geely's strategic transformation. Economic benefits created by Geely's employee proposals is growing, which has increased from 8.988 million yuan in 2005 to 54.43 million yuan in 2009 , indicating that the company is increasingly emphasizing the implementation of the proposals, and that the employees' concern have also been shifted from the small innovations gradually to the benefits brought by major innovations to the company.

\section{Conclusions and suggestions}

Development of the firm innovation system is an evolutionary process. Table 1 shows four generations of enterprise innovation systems. First generation firm innovation system considers internal $\mathrm{R} \& \mathrm{D}$ as the most valuable strategic asset and reliable guarantee, which is characterized by a closed independent innovation model. Second generation system is relatively complete and open, and "interaction" is the key word of this stage, which includes interactions between various departments within the enterprise $R \& D$ system, between $R \& D$ department and other departments, between manufacturer and customers or suppliers, as well as between the enterprise and other enterprises. The second generation system is an internally integrated, externally open innovation system. In the third generation highly strategic management-oriented enterprise innovation system, governance structure plays a central role in innovation. Fourth generation innovation ecosystem stresses "ecological" and "evolutionary" properties, whose aim is to provide the enterprises with a growing and evolving environment, promote the symbiotic evolution of related enterprises, and produce unexpected innovations. In the ecosystem building process, the fourth generation system further strengthens the construction of the corporate core competence, and values the accumulation and acquisition of basic R\&D and core technologies, thereby providing the integration of innovative resources with a clear direction, and reflecting enterprises', especially central enterprises' strategic and basic characteristics of technological innovation.

It should be stressed that the evolution of the enterprise innovation system is not a simple intergenerational replacement, but is a constantly superimposed and forward advancing process. The Innovation system is evolving toward ecological complexity. The future enterprise innovation system should be one that is based on core technologies and competencies, i.e., open innovation ecosystem based strongly on internal R\&D.

The focus of the enterprise technological innovation system is constant attention to the development of knowledge and competencies. Special attention should be particularly paid to the development of core competencies and technologies, the role of corporate executives and management teams in innovation decision-making and governance should be strengthened, the appointment of CINO whose rank is higher than chief engineer should be further strengthened, investment in R\&D, especially in advanced $R \& D$, should be further increased, and the

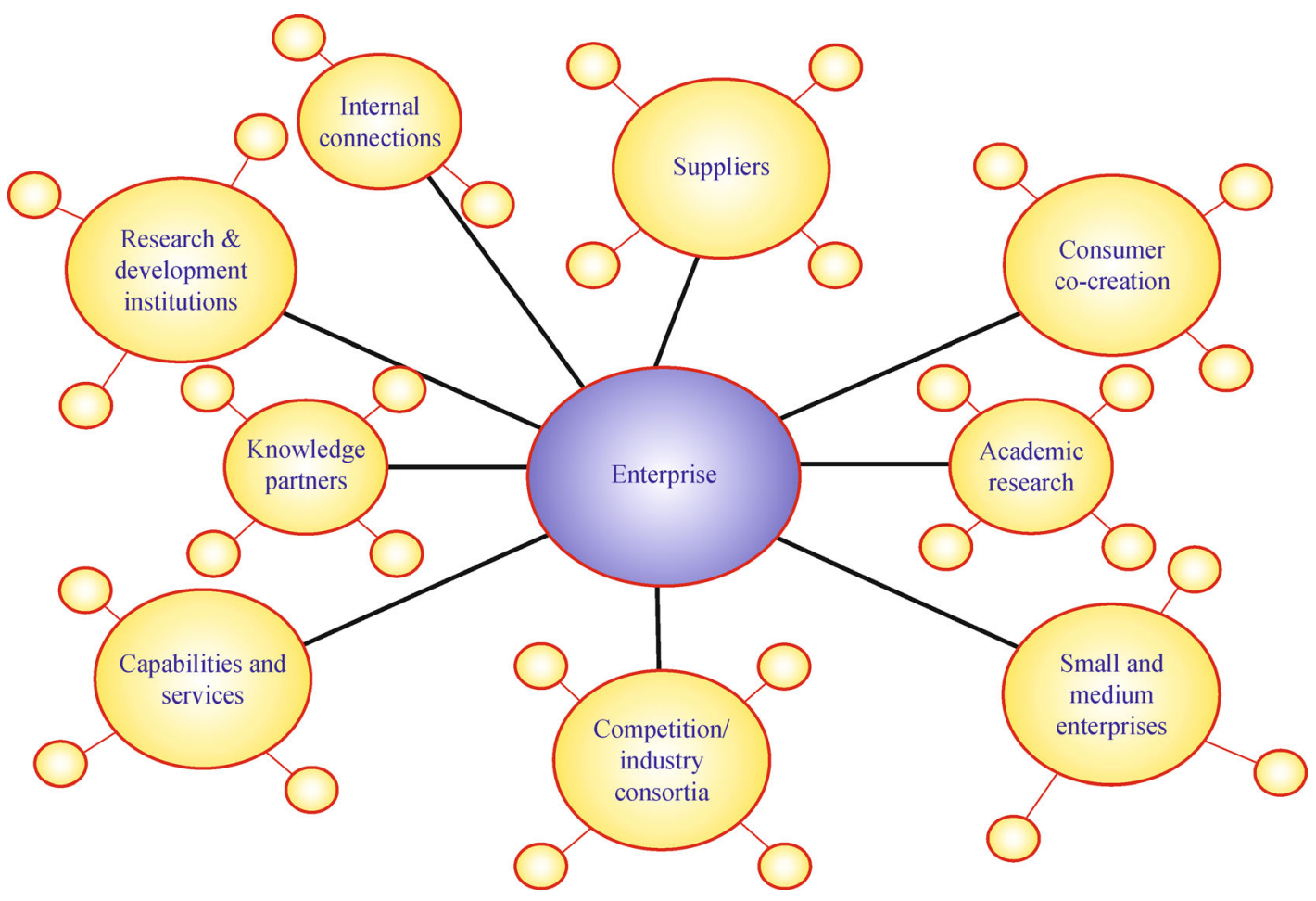

Figure 3. Enterprise ecosystem design. 
Table 1

Four Generations of Enterprise Innovation Systems

1st generation R\&D-Oriented Innovation System (1950s-mid 1960s)

Internal, independent

2nd generation Internal and External Collaboration Innovation System (1960s-mid 1980s)

Interactive, open

3rd generation Strategy-Oriented Innovation System (1980s-1990s)

Strategy, governance

4th generation Ecological Innovation System (1990s-future)

Ecological, core

construction of the enterprise technology center should be well proceeded while strengthening the construction of frontier technology-oriented enterprise research institutes, high-end R\&D and innovative talents, attaching importance to the development and promotion of skill-oriented talents and so on. Design of firm innovation system should also actively cross the outside boundaries, strengthen the cooperation with leading universities, research institutions and users, and actively launch technological merger and acquisition, in order to enrich and improve the enterprises' ability to obtain innovation resources, and actively integrate the discrete technological innovation achievements. The future enterprise innovation ability competition is a competition to show if the enterprises are able to build a core competence-based ecosystem.

\section{References}

Chen, J. (1999). System view and framework on the technological innovation. Journal of Management Sciences in China, 2, 66-73.

Chen, J., \& Chen, Y. (2007). The measurement of inputs of innovation resources under open innovation environment and policy meanings. Studies in Sciences of Sciences, 25, 352-359.

Chesbrough, H. (2003a). The era of open innovation. Sloan Management Review, 44, 35-41.

Chesbrough, H. (2003b). Open innovation: The new imperative for creating and profiting from technology. Boston, MA: Harvard Business School Press.

Cooke, P. (1992). Regional innovation systems: competitive regulation in the new Europe. Geoforum, 23, 365-382.

Cooke, P. (2004). Heidenreich, Braczyk HJ, Regional innovation systems. London: Routledge.

Demsetz, H. (1983). The structure of ownership and the theory of the firm. Journal of Law \& Economics, 26, 375-390.

Deschamps, J.P., \& Nelson, B. (2013). Innovation governance-how top management organizes and mobilizes for innovation. San Francisco,
CA: Jossey-Bass.

Freeman, C. (1987). Technology policy and economic performance: Lessons from Japan. London: Pinter Publishers.

Freeman, C. (1988). Japan: A new national system of innovation? Technicalchange and economic theory. London: Pinter Publishers.

Freeman, C. (1995). The national system of innovation in historical perspective. Cambridge Journal of Economics, 19, 5-24.

Iansiti, M., \& Levien, R. (2004). Strategy as ecology. Harvard Business Review, 82, 68-78, 126

Lundvall, B.A. (1988). Innovation as an interactive process: from userproducer interaction to the National Innovation Systems, technology and economic theory. London: Pinter Publishers.

Lundvall, B.A. (1992). National systems of innovation: towards a theory of innovation and interactive learning. London: Pinter Publishers.

Malerba, F. (2002). Sectoral systems of innovation and production. Research Policy, 31, 247-264.

Mowery, D., \& Rosenberg, N. (1979). The influence of market demand upon innovation: a critical review of some recent empirical studies. Research Policy, 8, 102-153.

Nelson, R.R. (1993). National systems of innovations: a comparative analysis. Oxford: Oxford University Press.

Ohmae K. (1991). The mind of the strategist: the art of Japanese business. McGraw-Hill Education Press.

Roberts. (2001). Benchmarking global strategic management of technology. Research Technology Management, 44(2), 25-36.

Schumpeter, J.A. (1912). Economic doctrine and method publication information. New York: Oxford University Press.

Teece, D.J. (1986). Profiting from technological innovation: Implications for integration collaboration, licensing and public policy. Research Policy, 15, 285-305.

Victor, W.H., \& Greg, H. (2012). The rainforest — the secret to building the next. California: Regenwald Press, 182-183.

Xu, Q., Xie, Z., \& Zheng, G. (2004). Institutional analysis on total innovation management. Science Research Management, 25, 6-12.

Zahra, S.A., \& Nambisan, S. (2012). Entrepreneurship and strategic thinking in business ecosystems. Business Horizons, 55, 219-229. 